\title{
ATP depletion and oxidative damage of hepatic cells following acute exposure to malathion in rat: beneficial role of porphyrin-fullerene nanoparticles carrying magnetic magnesium
}

\author{
Azam Bakhtiarian ${ }^{1}$, Mohammad Abdollahi ${ }^{2}$, Seyed Mahdi Rezayat ${ }^{1,3,4}$, Hamidreza Mohammadi ${ }^{5,6^{*}}$ \\ ${ }^{1}$ Department of Pharmacology, School of Medicine, Tehran University of Medical Sciences, Tehran, Iran \\ ${ }^{2}$ Faculty of Pharmacy and Pharmaceutical Sciences Research Center, Tehran University of Medical Sciences, Tehran, \\ Iran \\ ${ }^{3}$ Faculty of Advanced Sciences and Technology in Medicine, Tehran University of Medical Sciences, Tehran, Iran \\ ${ }^{4}$ Pharmaceutical Science Branch, Islamic Azad University, Tehran, Iran \\ ${ }^{5}$ Pharmacutical Science Research Center, Hemoglobinopathy Institute, Mazandaran University of Medical Sciences, \\ Sari, Iran \\ ${ }^{6}$ Department of Toxicology and Pharmacology, Faculty of Pharmacy, Mazandaran University of Medical Sciences, \\ Sari, Iran
}

Received: Mar 15, 2015, Revised: May 5, 2015, Accepted: June 14, 2015

\begin{abstract}
The objective of the present study was to investigate the role of nanocarrier of magnetic isotope of $25-\mathrm{Mg}^{2+}$ (PMC16) in liver toxicity, ATP content and oxidative stress due to malathion (MAL) exposure. PMC16 nanoparticles were administered in different doses $(0.05$, 0.1 and $\left.0.2 \mathrm{LD}_{50}\right)$ intravenously (iv) 40 minutes after a single MAL $\left(0.25 \mathrm{LD}_{50}=207 \mathrm{mg} / \mathrm{kg}\right)$ intraperitoneal (ip) injection as a complement to standard therapy of pralidoxime (PAM) and atropine (AT). $\mathrm{MgSO}_{4}$ was used as another supplement for comparison with PMC16. ATP/ADP ratio, antioxidant enzymes including catalase (CAT), glutathione peroxidase (GPx), superoxide dismutase (SOD), and oxidative stress biomarker including lipid peroxidation (LPO) were evaluated in liver tissue cells. Results indicated that after MAL administration, ADP/ATP ratio had a significant increase in liver tissues in comparison with control but this ratio was improved using various doses of PMC16. LPO was significantly decreased at all doses of PMC16 and $\mathrm{MgSO}_{4}$ when compared with MAL-exposed group. SOD and CAT activities significantly were increased in MAL-treated group as compared to saline group. SOD was reduced by all doses of PMC16 and CAT activity was decreased in PMC160.1 group. These results lead us to conclude that $\mathrm{PMC16}$ and $\mathrm{MgSO}_{4}$ are so useful for protection against MAL-induced liver toxicity, ATP depletion and oxidative damages.
\end{abstract}

Keywords: Organophosphate, malathion, magnesium, nanocarrier, adenosine triphosphate, oxidative stress

DOI: 10.18869/acadpub.pbr.1.2.10

\section{Introduction}

The organophosphate compounds (OPs) are among the most widely used pesticides in the world and thus is the cause of acute and chronic toxicities in human. Mitochondria are one of the targets of OPs toxicity as recently reviewed (1). The mitochondrial toxicity mostly appears by a reduction in cellular production of energy meaning adenosine triphosphate (ATP) that finally results in cell death. There is evidence that OP-induced hypoxia cause the induction of mitochondrial dysfunction because of the

* E-mail: $\underline{\text { hmohammadi@farabi.tums.ac.ir }}$ 
severe cellular damage, followed by bioenergetics failure which leads to necrotic cell death because of ATP depletion. Also, OPs induce cholinergic receptorindependent necrotic cell death by depressing the activity of complexes I to IV in the mitochondrial respiratory chain, eliciting decrease in mitochondrial transmembrane potential, depleting intracellular ATP contents, increasing lactate dehydrogenase release and damaging cell membrane integrity (2-4). It was determined that OPs produce oxidative stress in different tissues through the formation of reactive oxygen species (ROS) and induction of oxidative stress (5-8). Hypoxia condition and oxidative stress are in favor of apoptosis and necrosis in liver tissue. Previous investigations reported that OPs induced biochemical and histopathological changes in different tissues such as liver. $(9,10)$ The mechanism by which OPs induce liver toxicity has not been precisely illustrated and it is difficult to identify one individual mechanism as the cause of liver toxicity related to OPs. In recent years, studies have shown that oxidative stress is one of the main molecular mechanisms of toxicity of OPs. The liver is principally sensitive to this oxidative damage due to high oxidative metabolism and a very high cytochrome P450 activity related to the xenobiotics biotransformation process and hypoxia simultaneously.

Recently, the benefit of magnesium sulfate $\left(\mathrm{MgSO}_{4}\right)$ in the management of OP poisoning was reported by our team (11). $\mathrm{Mg}$ is essential for ATP activity including calcium current across and within cell membranes for cardiovascular tissues. Also, the benefit of $\mathrm{Mg}-25\left({ }^{25} \mathrm{Mg}^{2+}\right)$ carrying by a nanoparticle (PMC16) against toxicity of OPs in the heart cells (12) and cardiac activity was indicated (13). Magnetic magnesium isotope $\left({ }^{25} \mathrm{Mg}^{2+}\right)$ carrying by a nanoparticle called PMC16 which was previously introduced to have positive effects on production of cellular ATP (1416).

In the present study we aimed to evaluate the situation of liver in exposure to malathion (MAL), a commonly used OP in induction of liver toxicity, and to compare the protective effects of magnesium in the ordinary form of ${ }^{24} \mathrm{Mg}$ and in the form of PMC16. For this purpose we assessed the oxidative stress biomarkers and ADP/ATP ratio in the liver tissues.

\section{Materials and methods \\ Chemicals}

MAL (Shimi-Keshavarz Pesticide Production Co., Tehran), pralidoxime (PAM) from (SERB, Paris), NADPH, glutathione reductase, glutathione, glutathione peroxidase, sodium azide, adenosine diphosphate (ADP) sodium salt, adenosine triphosphate (ATP) disodium salt from Sigma-Aldrich Chemie (Gmbh, Munich, Germany), Tris base, methanol (HPLC-grade), malonedialdehyde (MDA), trichloroacetic acid (TCA), potassium hydroxide, diethyl ether, tetrabutylammonium hydroxide (TBAHS), $\mathrm{MgSO}_{4}$, n-butanol, 2-thiobarbituric acid (TBA), $\mathrm{KH}_{2} \mathrm{PO}_{4}$ (analytical grade), and $\mathrm{H}_{2} \mathrm{O}_{2}$ from Merck Chemical Co. (Tehran), and $\left({ }^{25} \mathrm{Mg}\right)$ PMC16 from Semenov institute (Russian Academy of Sciences), 2,7dichlorodihydrofluorescein diacetate (DCFD) from (Invitrogen), SUPELCOSILTM LC-18-T HPLC column from SUPELCO (UK) and SOD (superoxide dismutase) kit from Randox (UK) were used in this study.

\section{Animals and treatments}

All experiments were performed with male Wistar rats weighing 200-250 g obtained 
from Institute Pasteur of Tehran. The animals were housed in plastic cages in the temperature room $\left(22 \pm 2{ }^{\circ} \mathrm{C}\right)$, with a $12 \mathrm{~h}$ light/dark cycle and fed with standard rat chow (Dampars, Iran). Following several days of acclimatization, they were randomly divided into eight groups of six animals. All animal experiments were carried out in agreement with the guidelines for the care and use of laboratory animals accepted by the Japanese Pharmacological Society and acts of the Ethical Committee of Tehran University of Medical Sciences. MAL $\left(207 \mathrm{mg} / \mathrm{kg}\right.$ equals $\left.0.25 \mathrm{LD}_{50}\right)$ was dissolved in saline and administered in a constant volume of $1 \mathrm{ml} / \mathrm{kg}$, intraperitoneally (ip). Stock solution of PMC16 was dissolved in saline $(\mathrm{pH}$ was adjusted at 7.86) and administered intravenous (iv) at doses of $44.8 \mathrm{mg} / \mathrm{kg}$ (0.05 LD50), $89.6 \mathrm{mg} / \mathrm{kg}\left(0.1 \mathrm{LD}_{50}\right)$, and $179.2 \mathrm{mg} / \mathrm{kg}$ (0.2 LD50). Atropine (AT) was dissolved in saline and administered ip at dose of $(40 \mathrm{mg} / \mathrm{kg})$. PAM was dissolved in saline and administered ip at dose of (40 $\mathrm{mg} / \mathrm{kg}) . \mathrm{MgSO}_{4}\left(7 \mathrm{H}_{2} \mathrm{O}\right)$ was dissolved in saline and administered iv at dose of (600 $\mathrm{mg} / \mathrm{kg}$ ). Control animals received only saline at an appropriate volume.

The rats were randomly divided into 8 groups as follows:

Group 1: received saline alone named Saline;

Group 2: received only MAL named MAL; Group 3: received $\mathrm{MAL}+\mathrm{AT}+\mathrm{PAM}+\mathrm{MgSO}_{4}$ named $\mathrm{MgSO}_{4}$; Group 4: received MAL+AT+PAM+PMC16 $\left(0.05 \quad\right.$ LD $\left._{50}\right)$ named PMC16-0.05;

Group 5:

MAL+AT+PAM+PMC16 named PMC16-0.1;

Group 6:

$\mathrm{MAL}+\mathrm{AT}+\mathrm{PAM}+\mathrm{PMC} 16$

named PMC16-0.2;
Group 7: received MAL+AT+PAM named AT+PAM;

Group 8: received MAL+PMC16 (0.05 LD50) named only PMC16-0.05;

After 24 hours of the treatment, rats were anesthetized by administration of ether and underwent laparotomy. Liver tissues were dissected out and rinsed in ice-cold saline to remove the blood and immediately frozen and stored at $-80{ }^{\circ} \mathrm{C}$ for various assays. Before analyzing, tissues were homogenized in $50 \mathrm{mM}$ phosphate buffer solution ( $\mathrm{pH}$ 7.4) using a tissue homogenizer at $4{ }^{\circ} \mathrm{C}$. The homogenates were centrifuged at $3500 \times \mathrm{g}$ for $20 \mathrm{~min}$ and the supernatant was used for analyses.

\section{Measurement of lipid peroxidation (LPO)}

LPO was measured by the reaction of TBA with MDA and other lipid peroxides. Samples were mixed with TCA $(20 \%)$ and produced precipitate which was dispersed in $\mathrm{H}_{2} \mathrm{SO}_{4}(0.05 \mathrm{M})$. After addition of TBA ( $0.2 \%$ in sodium sulfate), the sample was heated for $30 \mathrm{~min}$ in a boiling water bath. Then LPO adducts were extracted by nbutanol and absorbance was measured with spectrophotometer UV 160-A (Shimadzu Japan) at $532 \mathrm{~nm}$ (13).

\section{Measurement of catalase (CAT)}

CAT activity was measured at $20{ }^{\circ} \mathrm{C}$ by monitoring the decomposition of $19 \mathrm{mM}$ hydrogen peroxide solution prepared in potassium phosphate buffer. The disappearance of $\mathrm{H}_{2} \mathrm{O}_{2}$ was monitored at $240 \mathrm{~nm}$ in $1 \mathrm{~min}$ intervals for $5 \mathrm{~min}$. Specific activity of the enzyme was expressed as micromoles per milligram protein as described previously 
Measurement of glutathione peroxidase $(G P x)$

The reaction that GPx catalyzes is: $2 \mathrm{GSH}+$ $\mathrm{H}_{2} \mathrm{O}_{2} \rightarrow$ GS-SG $+2 \mathrm{H}_{2} \mathrm{O}$, where GSH represents reduced monomeric glutathione, and GS-SG represents glutathione disulfide. Glutathione reductase then reduces the oxidized glutathione to complete the cycle: GS-SG + NADPH + $\mathrm{H}^{+} \rightarrow 2 \mathrm{GSH}+\mathrm{NADP}^{+}$. The assay mixture contained of $0.1 \mathrm{M}$ phosphate buffer $(\mathrm{pH}$ 7.4), $1 \mathrm{mM}$ GSH, $1 \mathrm{mM}$ EDTA, $0.2 \mathrm{mM}$ NADP $(\mathrm{H}), 1 \mathrm{mM}$ sodium azide, $0.25 \mathrm{mM}$ $\mathrm{H}_{2} \mathrm{O}_{2}$ and $1 \mathrm{mg}$ of homogenized tissues. NADP (H) oxidation was evaluated spectrophotometrically at $340 \mathrm{~nm}$.

\section{Measurement of superoxide dismutase (SOD)}

According to the kit method, xanthine and xanthine oxidase produce superoxide radicals which react with 2-(4-iodophenyl)3-(4-nitrophenol)-5-phenyltetrazolium chloride (INT) to form a red formazan dye. The SOD activity was calculated by the degree of inhibition of this reaction in homogenized tissues. One unit of SOD causes a 50\% inhibition of the rate of reduction of INT under the conditions of the assay. Data were presented as unit/mg protein (12).

\section{Measurement of ADP and ATP}

For the evaluation of the ATP/ADP ratio, tissues were sonicated in $250 \mu \mathrm{L}$ of trichloroacetic acid (TCA) (6\%) and centrifuged at $12,000 \mathrm{~g}$ for $10 \mathrm{~min}$ at $4{ }^{\circ} \mathrm{C}$. The supernatant was detached and neutralized with $\mathrm{KOH}(4 \mathrm{M})$. The cleaning of samples was done using a solid phase extraction (SPE) cartridge (C18, 22\%, 100 $\mathrm{mg} / 1 \mathrm{ml}$ ). Detection was achieved by HPLC system (Waters Chromatography Division, Milford, MA, USA) consisted of Waters 510 pump and solvent delivery system, column (SUPELCOSIL ${ }^{\text {TM }}$ LC-18-
T) with guard column holder and Waters 486 ultraviolet-visible detector. The flow rate was $1 \mathrm{ml} / \mathrm{min}$ for $20 \mathrm{~min}$ and detection was at $254 \mathrm{~nm}$. The levels of ATP and ADP were quantified after creating of standard curve, and the ADP/ATP ratio was calculated (18).

\section{Measurement of protein}

Samples were mixed with Bradford regent dye and after $5 \mathrm{~min}$, the absorbance was measured at $595 \mathrm{~nm}$ by the spectrophotometer using bovine serum albumin as a standard.

\section{Statistical analysis}

All data are expressed as mean \pm SEM. Statistical analysis was performed with oneway ANOVA followed by Tukey post hoc test for multiple comparisons. $\mathrm{P}<0.05$ was considered significant.

\section{Results}

ADP/ATP ratio

The effect of PMC16 on ADP/ATP ratio was investigated by assessing ADP and ATP levels in homogenated tissues of rat liver. MAL significantly increased $\mathrm{ADP} / \mathrm{ATP}$ ratio in liver tissues as compared with saline group $(\mathrm{P}<0.05)$. The ADP/ATP ratios decreased significantly in three doses of PMC16 and $\mathrm{MgSO}_{4}$ groups as compared with MAL group (Fig. 1).

\section{$\angle P O$}

LPO level was measured by assessing TBARS level in homogenated of rat liver tissues. TBARS levels were significantly increased in the MAL-exposed group (P < 0.001 ) in comparison to saline group in liver tissues (Fig. 2). LPO was significantly decreased in only- PMC16 $(\mathrm{P}<0.05)$, PMC16-0.05 $\quad(\mathrm{P}<0.05), \quad$ PMC16-0.1 ( $\mathrm{P}<0.05)$, PMC16-0.2 ( $<0.001)$, and $\mathrm{MgSO}_{4}(\mathrm{P}<0.01)$ in liver tissues when compared to the MAL group. 


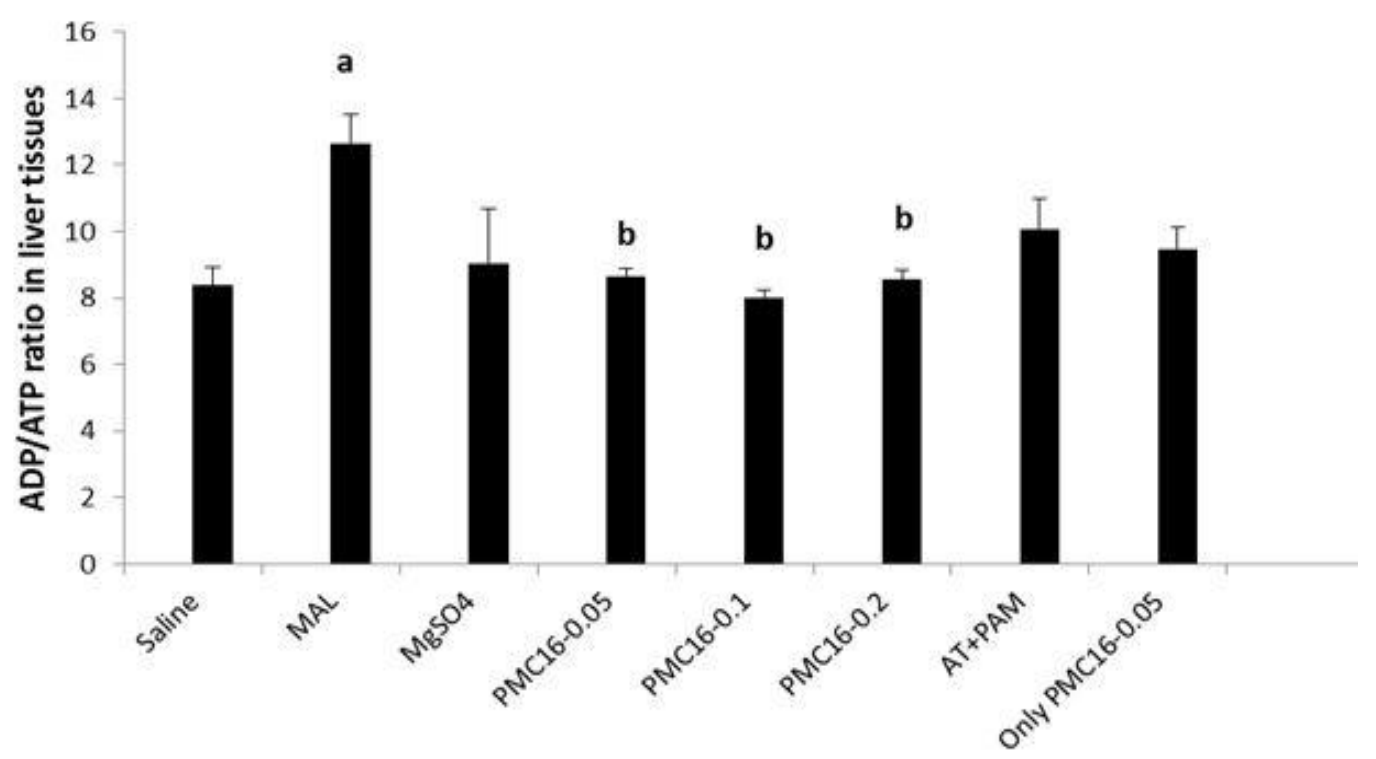

Figure 1 Effect of therapy on ADP/ATP ratio in liver tissues. Data are mean \pm SE of 6 animals in each group. Significantly different from saline group at $\mathrm{P}<0.05$ (a). Significantly different from MAL group at $\mathrm{P}<0.05$ (b).

\section{CAT}

Fig. 3 represents the effect of doses of PMC16 on CAT activity in liver rat tissues.CAT activity significantly increased $(\mathrm{P}<0.01)$ in MAL group in comparison to Saline group. A significant decrease in the CAT activity was found in the PMC16-0.1 group $(\mathrm{P}<0.01)$ in comparison to MAL group.

\section{$S O D$}

A significant increase in the SOD activity was found in Mal group as compared to saline group $(\mathrm{P}<0.05)$ (Fig. 4). SOD activity was significantly decreased in PMC16-0.05 (P < 0.01), PMC16-0.1 $(\mathrm{P}<0.05)$, PMC16-0.2 $(\mathrm{P}<0.001)$ and even in only PMC16 $(\mathrm{P}<0.05)$ groups in comparison to MAL group.

\section{$G P x$}

As shown in Fig. 5, no significant changes were found in GPx activity in different experimental groups.

\section{Discussion}

The results of this study indicate that MAL in acute exposure at a dose of 0.25 LD50 significantly increased liver ADP/ATP ratio and PMC16 in all doses used, surprisingly compensated the need of liver to ATP via increasing of ATP in hepatocytes. In addition, PMC16 reduced significantly MAL-induced LPO.

Previous studies demonstrated that OPs induce hypoxia, bradycardia, and mitochondrial dysfunction followed by depletion of cellular energy and death. This effect of MAL is mediated by inhibition of mitochondrial complexes I to IV and the respiratory chain and damaging cell membrane integrity $(3,19,20)$. Nowadays, a membranotropic new magnetic magnesium $\left({ }^{25} \mathrm{Mg}^{2+}\right)$ carrying by fullerene nanoparticles with low toxicity has been developed. This nanoparticle, which contains obvious cationite properties, is the iron containing porphyrin monoadduct of a classical buckminster fullerene named 'Porphylleren-MC16' or briefly PMC16. In 


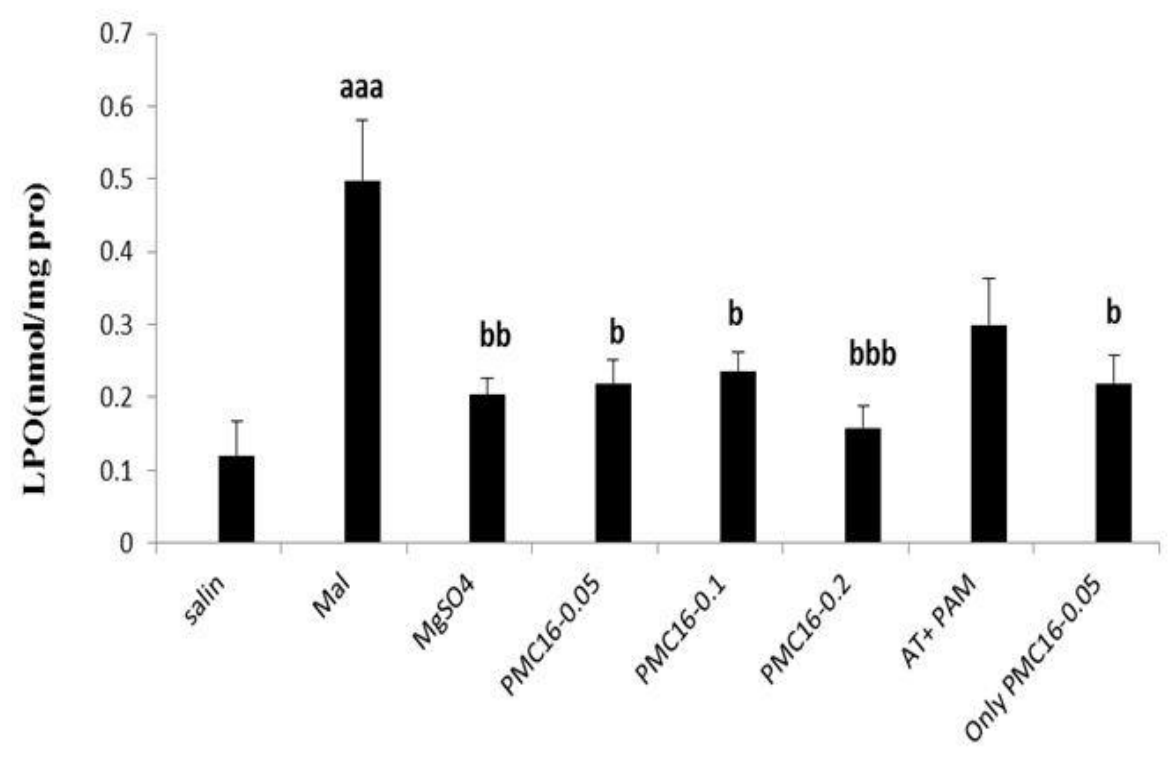

Figure 2 Changes in lipid peroxidation as thiobarbituric acid reactive substance (TBARS) in liver tissues. Data are mean \pm SE of 6 animals in each group. Significantly different from Saline group at $\mathrm{P}<0.001$ (aaa).Significantly different from malathion (MAL) group at $\mathrm{P}<0.001$ (bbb), $\mathrm{P}<0.01$ (bb), $\mathrm{P}<0.05$ (b).

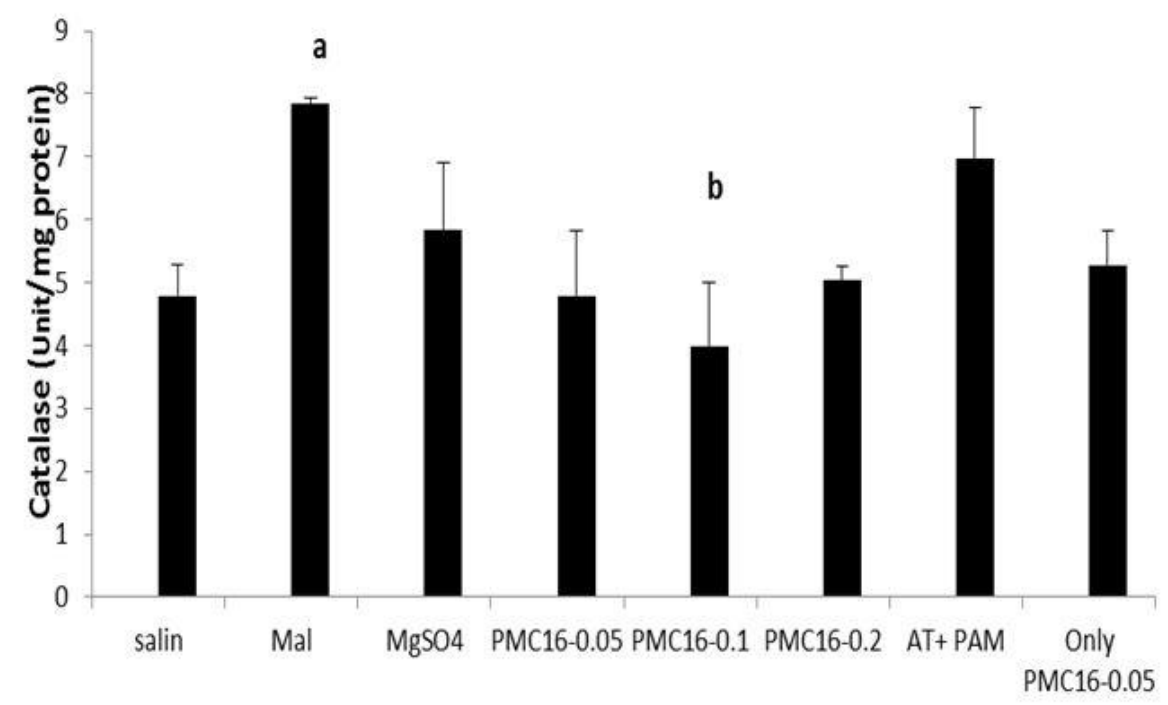

Figure 3 Changes in Catalase Activity in liver tissues in various groups. Data are mean \pm SE of 6 animals in each group. Significantly different from saline group at $\mathrm{P}<0.05$ (a). Significantly different from malathion (MAL) group at $\mathrm{P}<0.05$ (b). 


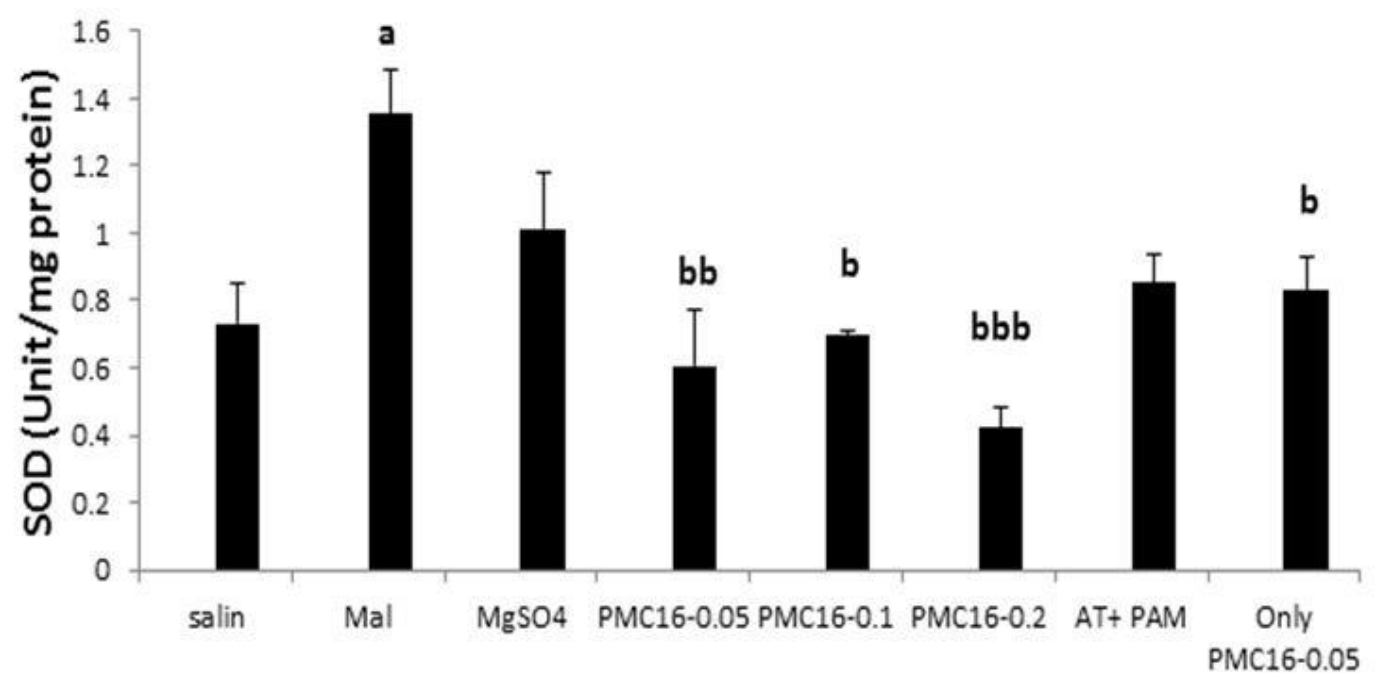

Figure 4 Changes in SOD activity in liver tissues in various groups. Data are mean \pm SE of 6 animals in each group.Significantly different from saline group at $\mathrm{P}<0.05$ (a). Significantly different from MAL group at $\mathrm{P}<0.001(\mathrm{bbb}), \mathrm{P}<0.01(\mathrm{bb}) \mathrm{P}<0.05(\mathrm{~b})$.

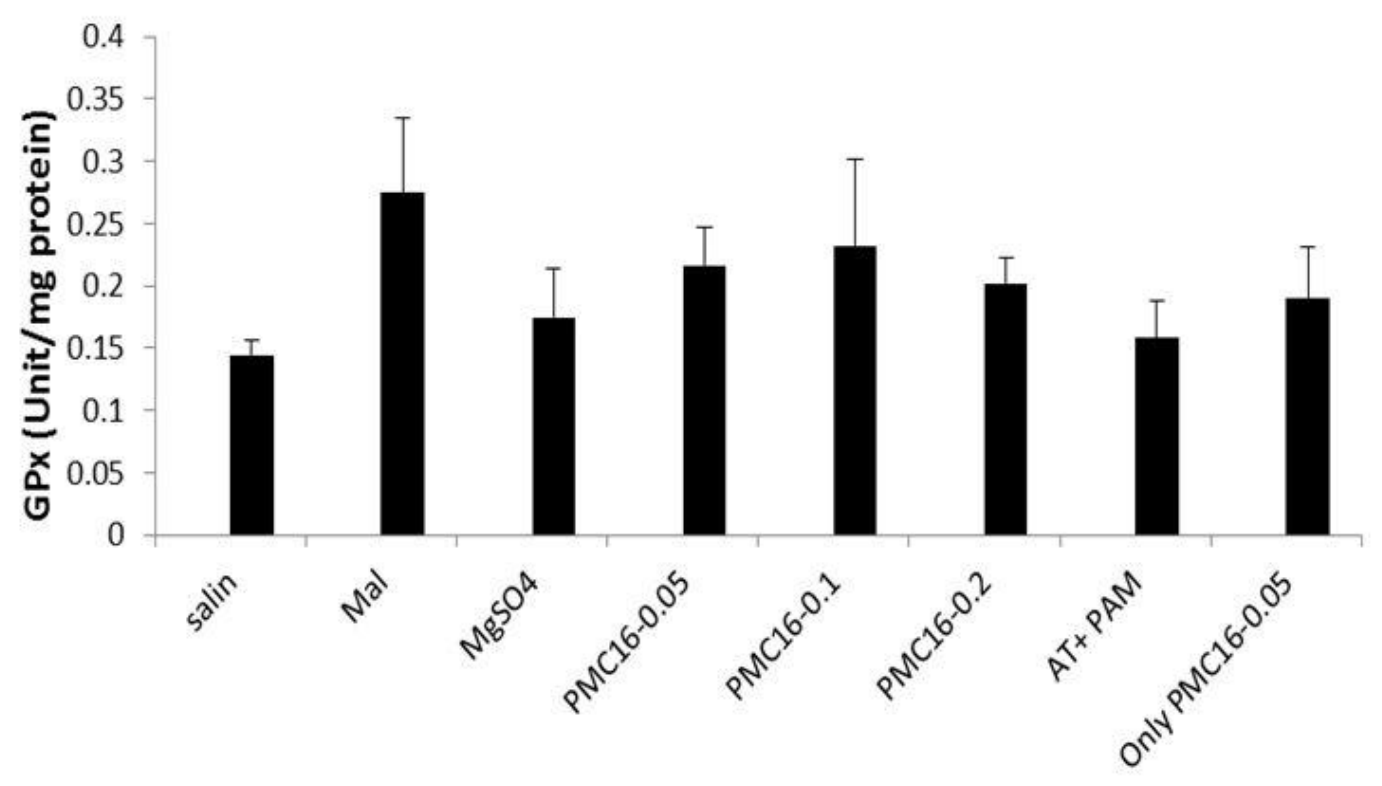

Figure 5 Changes in GPx Activity in liver tissues in various groups. Data are mean $\pm \mathrm{SE}$ of 6 animals in each group. 
acidosis condition these nanoparticles release the magnetic isotopes $\left({ }^{25} \mathrm{Mg}\right)$ and activate both oxidative phosphorylation and substrate pathways and creatine kinase (CK)-directed ADP phosphorylation inside the mitochondrial membranes in the cells (21).

According to previous studies, PMC16 is designed for a targeted delivery to compensate the ATP losses due to hypoxiacaused owing to a known ${ }^{25} \mathrm{Mg}$-related overactivation of both oxidative and substrate ADP phosphorylation pathways of the mitochondrial . ATP synthesis by ${ }^{25} \mathrm{Mg}^{2+}$, the only magnetic magnesium isotope, is activated up to 2.5 -fold more efficiently as compared to non-magnetic ${ }^{24}$ $\mathrm{Mg}^{2+}$ and ${ }^{26} \mathrm{Mg}^{2+}$ isotopes. Therefore, the acidosis-induced cause release of ${ }^{25} \mathrm{Mg}^{2+}$ from the $\left({ }^{25} \mathrm{Mg}\right)$ PMC16 cations towards the cells and tissues suffering from any type of hypoxia in vivo administration $(21,22)$. Moreover, a high level of synergism manifested between the CK activity, magnesium isotopes content and ATP production rate in mitochondria and tissue acidosis degree by the PMC16 hypoxia treated cases. It should be mentioned that PMC16 does not have more affinity to hepatocytes but in this study PMC16 has increased ATP production in liver cells and prevented the disturbance in the cells by balancing their energy with a negligible amount in treated groups. This study revealed that PMC16 also has a membrane protective and LPO inhibitory effects in liver tissues that confirm our previous studies $(20,23)$. Demonstrated that OPs induce oxidative stress and ROS generation is one of the important of molecular mechanism of toxicity. Induced oxidative stress by Ops causes mitochondrial energy depletion (ATP depletion), induction of proteolytic enzymes and DNA fragmentation which consequences lead to necrosis or apoptosis. ROS formation can be due to decrease rate of ATP synthesis in the mitochondria (3).

In this research although antioxidant enzymes were increased after MAL administration in MAL group as compared to saline group, PMC16 declined the activity of SOD in all used doses and CAT changed only in PMC16-0.1group. The first thing that comes to mind is the increased antioxidant power of liver reflects an activation of the compensatory mechanism through the effect of MAL on progenitor cells with its extent depending on the magnitude of the oxidative stress and therefore, on the dose of the stressor. Supporting this idea, there is evidence that administration of MAL increases the activities of CAT and SOD in erythrocytes and liver (8). No significant changes of the liver antioxidant enzymes may be due to the acute nature of the present model of the MAL poisoning or can supports this idea that PMC16 has free radical scavenger effects which this mechanism may be rather than an indirect antioxidant enzymes activation. Regarding, better efficacy of some doses of PMC16 than normal magnesium $\left({ }^{24} \mathrm{Mg}\right.$ in $\left.\mathrm{MgSO}_{4}\right)$ was seen in this study. It is prominent to affirm that the exceptional structure of PMC16 allows it to provide as a nanocationite with capability of releasing magnetic magnesium into hypoxic cells, in that way cause considerable enhancement of the oxidative phosphorylation pathway. Moreover, PMC16 has the porphyrin domain which provides a tissue selective interaction for porphyrin receptors located in mitochondrial membrane (24). In supporting of the present study, $\mathrm{Mg}$ has been found valuable in human OPs poisoning management by modulation of oxidative stress condition and reducing of the cellular ROS formation (11). Efficacy of PMC16 compared with other forms of $\mathrm{Mg}$ supports this idea that ${ }^{25} \mathrm{Mg}$ plays an 
essential role in $\mathrm{Mg}$-dependent production of ATP which consistent with the previous findings $(14,15,23)$. Therefore, the PMC16 activity is dependent on delivery of ${ }^{25} \mathrm{Mg}$ isotope towards the hypoxia distressing cells and tissues.

Another hypothesis is that PMC16 molecules or its metabolites may react with MAL molecule and neutralize its electrophilic sites. Although in our previous studies we have stated that antioxidant activity was decreased, and oxidant markers were increased in malathion toxicity, the studies on the relationship between oxidant and antioxidant status and the liver damage in acute MAL poisoning are limited $(6,7$, 23).

In conclusion, it is noteworthy that PMC16 is able to decrease OP-induced liver toxicity by prevention of ROS formation and elevation of ATP content in hepatic cells.

\section{References}

1. Abdollahi M, Karami-Mohajeri S. A comprehensive review on experimental and clinical findings in intermediate syndrome caused by organophosphate poisoning. Toxicol Appl Pharm 2012;258:309-14

2. Karami-Mohajeri, S. Abdollahi, M. Mitochondrial dysfunction and organophosphorus compounds. Toxicol Appl Pharm 2013;270:39-44.

3. Bagchi D, Bagchi M, Hassoun E, Stohs S. In vitro and in vivo generation of reactive oxygen species, DNA damage and lactate dehydrogenase leakage by selected pesticides. Toxicol 1995;104:129-40.

4. Chan JY, Chan SH, Dai K, Cheng HL, Chou JL, Chang AY. Cholinergic receptor-independent dysfunction of mitochondrial respiratory chain enzymes, reduced mitochondrial transmembrane potential and ATP depletion underlie necrotic cell death induced by the organophosphate poison mevinphos. Neuropharmacology 2006;51:1109-19.

5. Banerjee B, Seth V, Bhattacharya A, Pasha S, Chakraborty A. Biochemical effects of some pesticides on lipid peroxidation and free-radical scavengers. Toxicology lett 1999;107:33-47.

6. Abdollahi M, Mostafalou S, Pournourmohammadi S, Shadnia S. Oxidative stress and cholinesterase inhibition in saliva and plasma of rats following subchronic exposure to malathion. Comparative Biochemistry and Physiology Part C. Toxicol Pharm 2004;137:29-34.

7. Abdollahi M, Ranjbar A, Shadnia S, Nikfar S, Rezaie A. Pesticides and oxidative stress: a review. Med Sci Monitor 2004;10:141-7

\section{Acknowledgements}

The authors thank Dr Dmitry A. Kuznetsov from the Department of Medicinal Nanobiotechnoloies of N.I. Pirogoff Russian State Medical University for reading the paper and giving comments. The authors also thank Shokoufeh Hassani, Hoda Shafiee, Asieh Hosseini, Maryam Baeeri and Marjan Shariatpanahi for excellent technical support.

\section{Funding}

This work was supported in part by grant (\#10386) from Tehran University of Medical Sciences.

\section{Conflict of interest}

The authors declare that they have no competing interests.

8. Akhgari M, Abdollahi M, Kebryaeezadeh A, Hosseini R, Sabzevari O. Biochemical evidence for free radicalinduced lipid peroxidation as a mechanism for subchronic toxicity of malathion in blood and liver of rats. Hum Exp Toxicol 2003;22:205-11.

9. Orchard $\mathrm{CH}$, Kentish JC. Effects of changes of $\mathrm{pH}$ on the contractile function of cardiac muscle. Am J Physiol 1990;258:967-81.

10. Sutcu R, Altuntas I, Yildirim B, Karahan N, Demirin H, Delibas N. The effects of subchronic methidathion toxicity on rat liver: role of antioxidant vitamins $\mathrm{C}$ and $\mathrm{E}$. Cell Biol Toxicol 2006;22:221-7.

11. Pajoumand A, Shadnia S, Rezaie A, Abdi M, Abdollahi M. Benefits of magnesium sulfate in the management of acute human poisoning by organophosphorus insecticides. Hum Exp Toxicol 2004;23:565-9.

12. Shafiee H, Mohammadi H, Rezayat SM, Hosseini A, Baeeri M, Hassani S, et al. Prevention of malathioninduced depletion of cardiac cells mitochondrial energy and free radical damage by a magnetic magnesium-carrying nanoparticle. Toxicol Mech Meth 2010;20:538-43.

13. Mohammadi H, Karimi G, Rezayat SM, Reza A, Shafiee $\mathrm{H}$, Nikfar S, et al. Benefit of nanocarrier of magnetic magnesium in rat malathion-induced toxicity and cardiac failure using non-invasive monitoring of electrocardiogram and blood pressure. Toxicol Ind Health 2011;27:417-29.

14. Buchachenko A, Kouznetsov D, Arkhangelsky S, Orlova M, Markarian A. Spin biochemistry: Magnetic $24 \mathrm{Mg}-$ $25 \mathrm{Mg}-26 \mathrm{Mg}$ isotope effect in mitochondrial ADP phosphorylation. Cell Biochem Biophys 2005;43:243-51. 
15. Buchachenko A, Kouznetsov D, Orlova M, Markarian A. Magnetic isotope effect of magnesium in phosphoglycerate kinase phosphorylation. Proc Nat Acad Sci USA 2005;102:10793-6.

16. Buchachenko A, Kuznetsov D, Arkhangel'sky S, Orlova M, Markaryan A, Berdieva A, et al. Dependence of Mitochondrial ATP Synthesis on the Nuclear Magnetic Moment of Magnesium Ions. Dokl Biochem Biophys 2004;396:197-9

17. Sarkhail $\mathrm{P}$, Rahmanipour $\mathrm{S}$, Fadyevatan $\mathrm{S}$, Mohammadirad A, Dehghan G, Amin G, et al. Antidiabetic effect of Phlomis anisodonta: Effects on hepatic cells lipid peroxidation and antioxidant enzymes in experimental diabetes. Pharmacol Res 2007;56:261-6.

18. Hosseini A, Sharifzadeh M, Rezayat S. Benefit of magnesium-25 carrying porphyrin-fullerene nanoparticles in experimental diabetic neuropathy. Int J Nanomed 2010;5:517-23.

19. Chan J, Chan S, Dai K, Cheng H, Chou J, Chan A. Cholinergic receptor-independent dysfunction of mitochondrial respiratory chain enzymes, reduced mitochondrial transmembrane potential and ATP depletion underlie necrotic cell death induced by the organophosphate poison mevinphos Neuropharmacology 2006;51:1109-19.
20. Shafiee H, Mohammadi H, Rezayat S, Hosseini A, Baeeri M, Hassani S, et al. Prevention of malathioninduced depletion of cardiac cells mitochondrial energy and free radical damage by a magnetic magnesiumcarrying nanoparticle. Toxicol Mech Meth 2010; 20:538-43.

21. Amirshahi N, Alyautdin R, Sarkar S, Rezayat S, Orlova M, Trushkov I, et al. Porphyrin-fullerene nanoparticles for treatment of hypoxic cardiopathies. Nanotech Russia 2008;3:611-21.

22. Buchachenko A, Kouznetsov D, Breslavskaya NN, Orlova MA. Magnesium isotope effects in enzymatic phosphorylation. J Phys Chem B 2008;112: 2548-56.

23. Mohammadi HR, Karimi G, Rezayat SM, Dehpour AR, Shafiee H, Nikfar S, et al. Benefit of nanocarrier of magnetic magnesium in rat malathion-induced toxicity and cardiac failure using non-invasive monitoring of electrocardiogram and blood pressure. Toxicol Ind Health 2011;27:417-29.

24. Motohashi N, Takahashi A, Mifune M, Saito $\mathrm{Y}$. Inhibitory effects of water-soluble cationic manganese porphyrins on peroxynitrite-induced SOS response in Salmonella typhimurium TA4107/pSK1002. Mut Res Fund Mol Mech Mut 2004;554:165-74. 